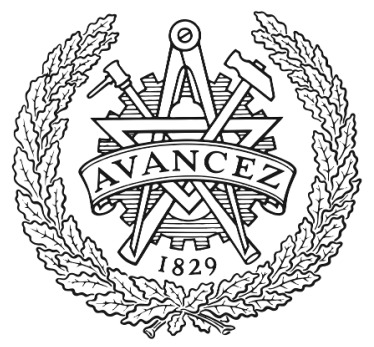

CHALMERS

UNIVERSITY OF TECHNOLOGY

\title{
Oxygen balance during laser powder bed fusion of Alloy 718
}

Downloaded from: https://research.chalmers.se, 2023-04-26 14:40 UTC

Citation for the original published paper (version of record):

Pauzon, C., Raza, A., Hryha, E. et al (2021). Oxygen balance during laser powder bed fusion of Alloy

718. Materials and Design, 201. http://dx.doi.org/10.1016/j.matdes.2021.109511

N.B. When citing this work, cite the original published paper. 


\title{
Oxygen balance during laser powder bed fusion of Alloy 718
}

\author{
Camille Pauzon $^{\mathrm{a}, *}$, Ahmad Raza $^{\mathrm{a}}$, Eduard Hryha ${ }^{\mathrm{a}}$, Pierre Forêt ${ }^{\mathrm{b}}$ \\ a Chalmers University of Technology, Department of Industrial and Materials Science, Rännvägen 2A, 41296 Gothenburg, Sweden \\ b Linde GmbH, Carl-von-Linde-Strasse 25, 85716 Unterschleissheim, Germany
}

\section{H I G H L I G H T S}

- An important oxygen transfer from the virgin powder and from the environment to the spatters occurs

- Some oxygen is lost from the virgin powder to the component ( $30 \mathrm{ppm})$ and preferentially transferred to spatters

- Degradation of Alloy 718 powder is observed as an increasing coverage of $\mathrm{Al}-/$ Cr-rich oxide features

- Spatters ejected from the melt pool experience higher cooling rates $\left(\sim 10^{8} \mathrm{~K} / \mathrm{s}\right)$ than entrained particles $\left(\sim 10^{6} \mathrm{~K} / \mathrm{s}\right)$

- Components with high surface-tovolume ratio promote powder degradation and oxygen pick-up of the powder bed

\section{A R T I C L E I N F O}

\section{Article history:}

Received 16 December 2020

Received in revised form 12 January 2021

Accepted 21 January 2021

Available online 23 January 2021

\section{Keywords:}

Additive manufacturing

Laser powder bed fusion

Process atmosphere

Spatter particles

Powder degradation

Residual oxygen
GRAPHICAL A B S T R A C T

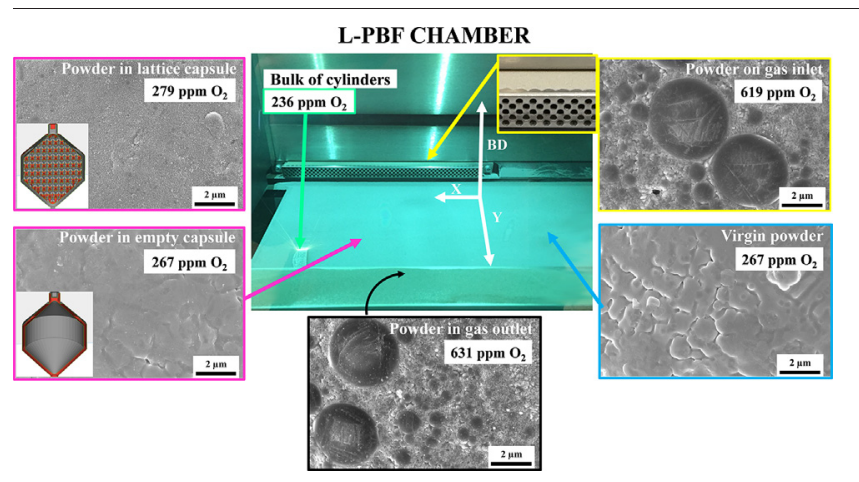

\begin{abstract}
A B S T R A C T
The generation of spatters during laser powder bed fusion (L-PBF) of Alloy 718 is known to be detrimental for the re-use of the feedstock powder and the quality of the final product. In this study, dedicated powder sampling from different positions within the build chamber and powder bed was performed. The results clearly indicate the importance of the surface-to-volume ratio of the built components on powder degradation, as demonstrated by the analysis of the powder using capsules filled with dense lattice structures. Extensive formation of Al- and $\mathrm{Cr}$-rich oxides on the entrained powder deposited on the gas inlet and outlet was detected. Significant oxygen pick-up by spatter particles compared to the virgin powder was measured $\left(>300 \mathrm{ppm} \mathrm{O}_{2}\right.$ ); while the as-built material experienced a slight loss $\left(\sim 30 \mathrm{ppm} \mathrm{O}_{2}\right)$. The change in the microstructure of spatter particles in comparison to the virgin powder, namely the primary dendrite arm spacing, indicates significantly higher cooling rate during spatter solidification, estimated to be of about $10^{8} \mathrm{~K} / \mathrm{s}$, compared to around $10^{6} \mathrm{~K} / \mathrm{s}$ for the virgin powder and $10^{7} \mathrm{~K} / \mathrm{s}$ for the L-PBF component. These findings allows to evaluate the extent of powder degradation during $\mathrm{L}-\mathrm{PBF}$ and establish the oxygen balance of the process.
\end{abstract}

(c) 2021 The Author(s). Published by Elsevier Ltd. This is an open access article under the CC BY license (http:// creativecommons.org/licenses/by/4.0/).

\footnotetext{
* Corresponding author.

E-mail address: pauzon@chalmers.se (C. Pauzon).
}

\section{Introduction}

Metal laser powder bed fusion (L-PBF) is associated with melting of metallic powder using a focused laser beam (about $100 \mu \mathrm{m}$ spot size). The local temperatures close to the laser spot were shown to overpass considerably the melting point and lead to the formation of metal 
vapors and fumes [1]. Among the materials processable by L-PBF today, many are sensitive to these high temperatures that promote diffusiondriven processes such as oxidation. Rich in $\mathrm{Ti}, \mathrm{Al}, \mathrm{Cr}$ and other elements of high affinity for oxygen [2,3], these materials are likely to form stable oxide species, which are then transferred to the produced parts whose mechanical properties can be compromised. To limit these harmful consequences, an inert gas flow ( $\mathrm{Ar}$ ) covers the build area to remove impurities close to the melt pool and heated material. The typically achieved oxygen level with industrial systems is close to $1000 \mathrm{ppm}$ of residual $\mathrm{O}_{2}$ [4]. In addition, a lot of effort is put into the optimization of the gas flow properties, e.g. through the design of the gas inlet and outlet, to enhance gas flow profiles to remove the impurities, vapors and process ejections, also called spatters [5-7].

Spatters may arise from two distinct origins. They can be produced as direct ejections from the unstable melt pool. This occurs when the convection forces surpass the surface tension within the melt. In general, the melt flow behavior is governed by both the vapor recoil pressure and the Marangoni effect $[8,9]$. These are highly dependent on the laser parameters employed, but also on the material's properties (composition, etc.) and that of the process gas used. The spatters can also be generated by gas- or vapor-induced entrainment [9], and consist mostly of entrained particles from the powder bed. Among these, some will interact with the moving laser, while others will have an uninterrupted trajectory. The interacting ones will lead to shadowing effects, which reduce the transmitted energy to the targeted powder bed. Usually experiencing elevated temperatures, spatters are likely to be rich in oxygen and oxides [10,11], and be precursors for structural defects in the produced part as they re-deposit on the powder bed. In general, they are undesirable for part's quality, powder recyclability and the lifetime of the recirculation filter system of the L-PBF machine.

Significant work has been conducted on related topics, such as the effect of residual impurities from the atmosphere on the properties of L-PBF produced material [12-14], transfer of oxygen from the feedstock powder to the produced material and its effect on the microstructure [15], characterization of spatter $[10,11,16]$ and powder recyclability [17]. Still, the understanding of the transfer of impurities from the feedstock powder to the built part and spatters is lacking.

The current work is connecting these aspects by establishing an impurity balance (oxygen and nitrogen) during the L-PBF processing of Alloy 718 which is sensitive to both, oxygen and nitrogen. This is actually the reason why Alloy 718 is usually cast under vacuum [18]. In this balance, re-distribution of oxygen and nitrogen from the feedstock powder and the processing gas as initial source of oxygen to the produced parts, the un-used powder and the spatter is considered. The effect of the process atmosphere purity is also addressed and connected to the mass balance established. The careful sampling of the powder samples combined with high resolution characterization techniques allowed to determine where and in which chemical form is the oxygen redistributed during the process. The detailed analysis of the morphology and microstructure of spatter particles explained their origin and criticality for defect formation in L-PBF and powder re-use.

\section{Materials and methods}

An EOS M290 (EOS GmbH) L-PBF machine was used to conduct the study. This system is equipped with an Yb-fibre laser of $400 \mathrm{~W}$ nominal power. The build job was designed to mimic an industrial printing, by maximizing the use of the build envelope $\left(250 \times 250 \times 325 \mathrm{~mm}^{3}\right)$, see Fig. 1. Four large cylinders ( $25 \mathrm{~mm}$ inside diameter, $80 \mathrm{~mm}$ outside diameter and $48 \mathrm{~mm}$ height) were placed around two powder capsules, one empty and one filled with a dense lattice structure. The lattice has a body-centered tetragonal unit cell ( $a=b=3 \mathrm{~mm} ; c=4 \mathrm{~mm})$, with 8 struts of $1 \mathrm{~mm}$ diameter corresponding to the cell diagonals. The standard EOS parameter for Alloy 718 were used with a $40 \mu \mathrm{m}$ layer thickness (under the license name: IN718_PerformanceM291 2.11) and consists in an optimized sequence of in-fill and contour scannings,

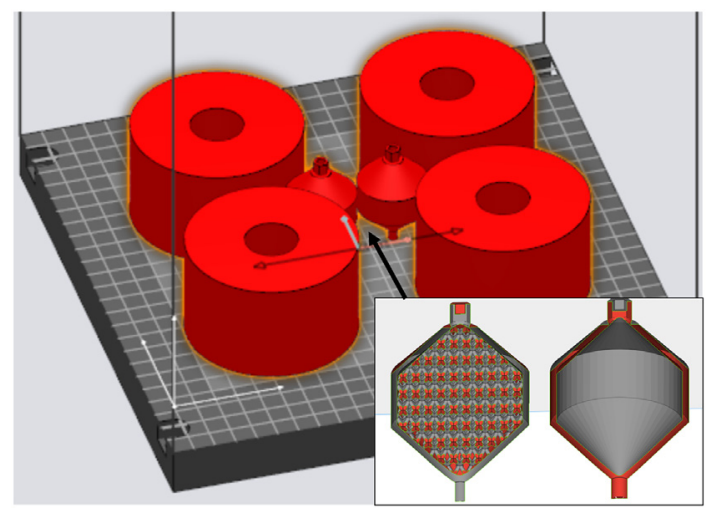

Fig. 1. Layout of the build job design consisting of four large cylinders and two powder capsules, one featuring a lattice of $1 \mathrm{~mm}$ diameter struts. For information, the associated table lists the mass of the produced parts and their surface. The mass of the capsules is indicated without the un-melted powder inside.

with the latter ensuring dimensional accuracy and good surface properties. The laser scanning is rotated by $67^{\circ}$ between each layer. High-quality argon (Argon 4.6) was used under normal operating condition, corresponding to a gas flow from the gas inlet towards the gas outlet of approx. $2 \mathrm{~m} / \mathrm{s}$ (see Fig. 3). The process atmosphere is established by flushing the build chamber (with initially about $21 \%$ $\mathrm{O}_{2}$ ) with the inert gas, the process is then initiated as soon as the oxygen sensor of the system detects a stable level of $0.1 \% \mathrm{O}_{2}$. The print job lasted about $21 \mathrm{~h}$.

The Alloy 718 powder used was gas atomized and had particles size in the range of $15 \mu \mathrm{m}$ to $45 \mu \mathrm{m}$ and was provided by Höganäs $A B$, Sweden. The particle size distribution (PSD) was verified by laser diffraction using a Mastersizer 3000 (Malvern Panalytical). The results of five measurements provided the following average data: $\mathrm{D}_{10}=17.8 \pm 0.1 \mu \mathrm{m}$, $\mathrm{D}_{50}=30.1 \pm 0.1 \mu \mathrm{m}, \mathrm{D}_{90}=49.5 \pm 0.2 \mu \mathrm{m}$, and the complete distribution is presented in Fig. 2c. Fig. 2 displays micrographs of the surface morphology of this virgin powder. While some amount of satellites can be observed (see Fig. 2a), the overall surface appears clean and grain/dendrite boundaries can be distinguished upon high magnification (Fig. 2b). Fig. 2d highlights the presence of large particles reaching up to $60 \mu \mathrm{m}$ in diameter belonging to the high end of the PSD.

When the previously described build job was completed, powder samples were collected at different locations in the build chamber: on top of the gas inlet and outlet, in the gas outlet, and in the powder capsules, to be compared to the feedstock powder in its virgin state, see Fig. 3. The gas outlet is composed of several sections separated by thin metallic walls. The sections from which powder samples were collected are named 1st to 5 th from left to right, see bottom of Fig. 3 .

The powder samples collected were used to conduct chemical analysis, surface morphology analysis and microstructure analysis. The chemical analysis was performed by combustion technique using a LECO ON836. For surface morphology analysis by SEM and surface chemistry analysis by XPS, samples were prepared by soft pressing of the powder between two indium plates. These samples were analysed by high resolution scanning electron microscopy (HR SEM) with a LEO Gemini 1550. The microstructure of the powder was also documented by HR SEM on their polished cross-section. Some of the as-built material was also analysed, to compare obtained microstructures to that of the powder particles. Etching was performed on polished cross-section by swabbing Kalling's reagent No.2. Primary and secondary dendrite arm spacing (PDAS and SDAS) were measured on the cross-section of particles from the collected samples using the Image J software [19] to estimate cooling rates.

X-ray photoelectron spectroscopy (XPS) was used to identify the elements and their chemical state present on the surfaces of the sampled powders using a PHI 5500 (ULVAC-PHI) instrument equipped 

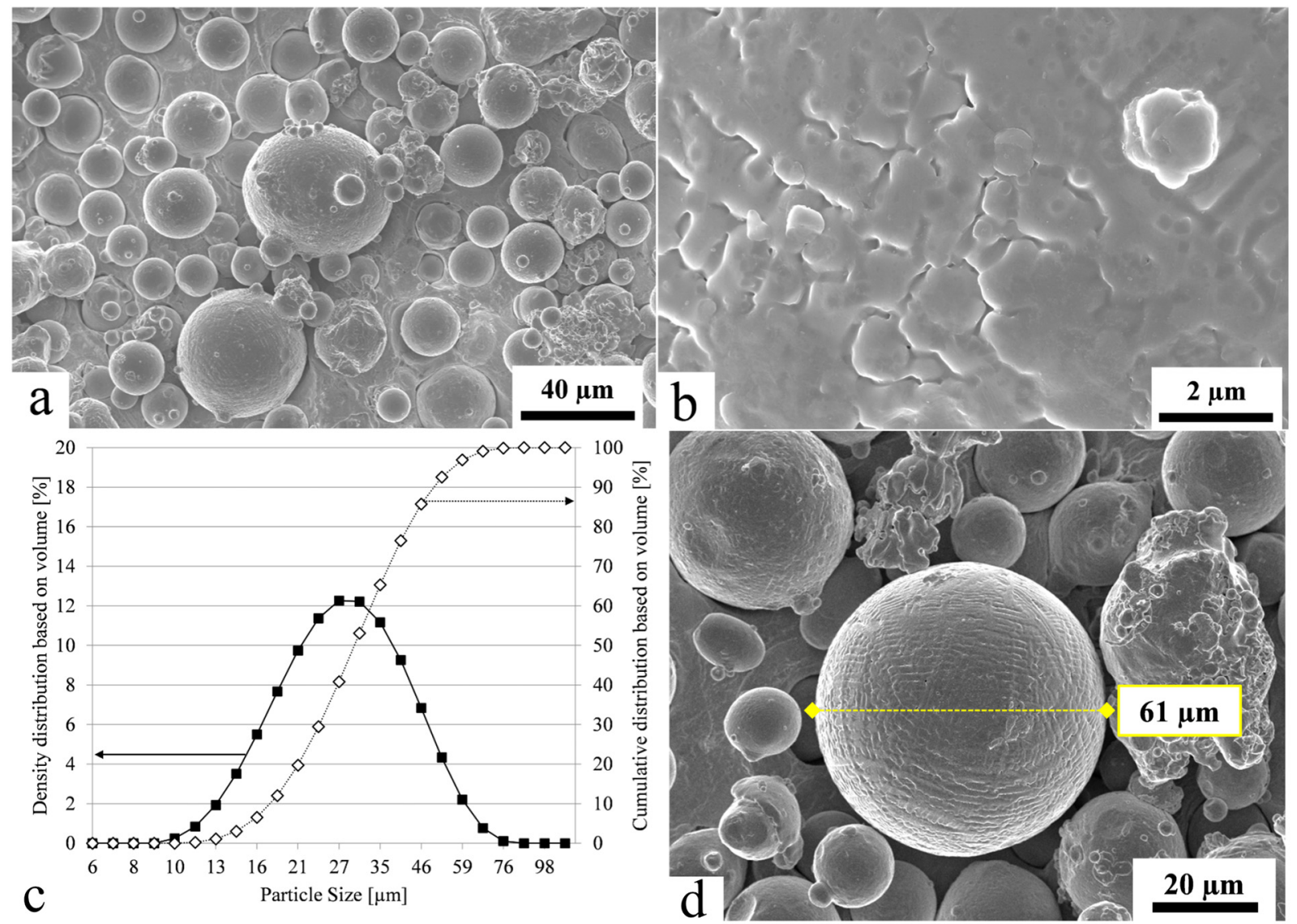

Fig. 2. (a) SEM micrograph of the virgin Alloy 718 powder employed in the present work (magnification x500); (b) high magnification (x10000) of the surface morphology of one powder particle.

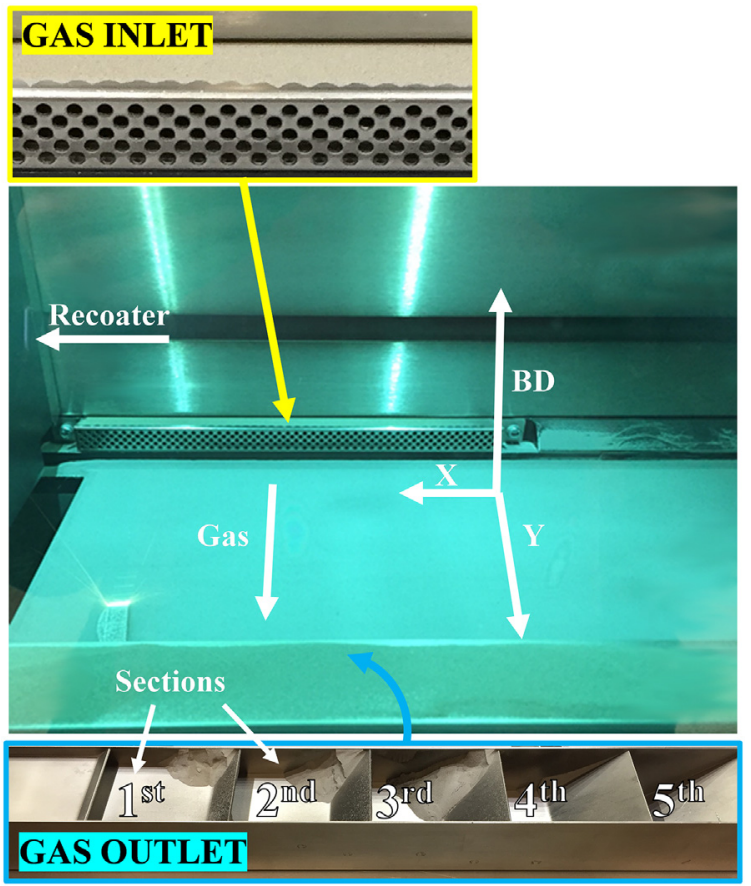

Fig. 3. Photograph of the build chamber seen from the outside of the machine through the window of the door. Close-up pictures display the gas outlet at the front and the gas inlet at the back of the build area. The gas outlet has several sections; the ones from which particles were collected are numbered from 1 st to 5 th. with a monochromatic $\mathrm{Al} \mathrm{K \alpha}(1486.6 \mathrm{eV}) \mathrm{X}$-ray source for the generation of photoelectrons. The analysed area was about $0.2 \mathrm{~mm}$ in diameter for the used aperture size. As a result, a lot of particles are analysed at the same time, therefore giving an average representative result of the general powder surface state of the samples. Alternation between XPS analysis and ion etching $\left(\mathrm{Ar}^{+}\right)$allowed to record depth profiles. The ion etching rate of $4 \mathrm{~nm} / \mathrm{min}$ was calibrated on a flat oxidized tantalum foil. High resolution narrow scans over the binding energy of the elements of interest were collected by using pass energy of $26 \mathrm{eV}$.

Table 1

The mass of the Alloy 718 powder sampled at different sites and corresponding contents of oxygen and nitrogen. Oxygen and nitrogen analyses of the virgin powder and as-built components are presented for comparison as well.

\begin{tabular}{llll}
\hline Sample & Mass $[\mathrm{g}]$ & $\mathrm{O}[\mathrm{ppm}]$ & $\mathrm{N}[\mathrm{ppm}]$ \\
\hline Virgin powder & $\mathrm{N} / \mathrm{A}$ & 267 & 66 \\
Cylinder & 1772 & 236 & 66 \\
Powder in lattice-free capsule & 67.5 & 267 & 68 \\
Powder in capsule with lattice & 43.5 & 279 & 68 \\
On the inlet & 2.4 & 619 & 77 \\
On the outlet & 20 & 569 & 69 \\
In the 1st section of the outlet & 5.9 & 691 & 73 \\
In the 2nd section of the outlet & 9.9 & 670 & 75 \\
In the 3rd section of the outlet & 20 & 631 & 74 \\
In the 4th section of the outlet & 1.5 & 579 & 76 \\
In the outlet & & Not measured & Not measured \\
\hline
\end{tabular}

a Corresponds to the powder collected inside the gas outlet in the common section where the individual sub-sections are connected. 


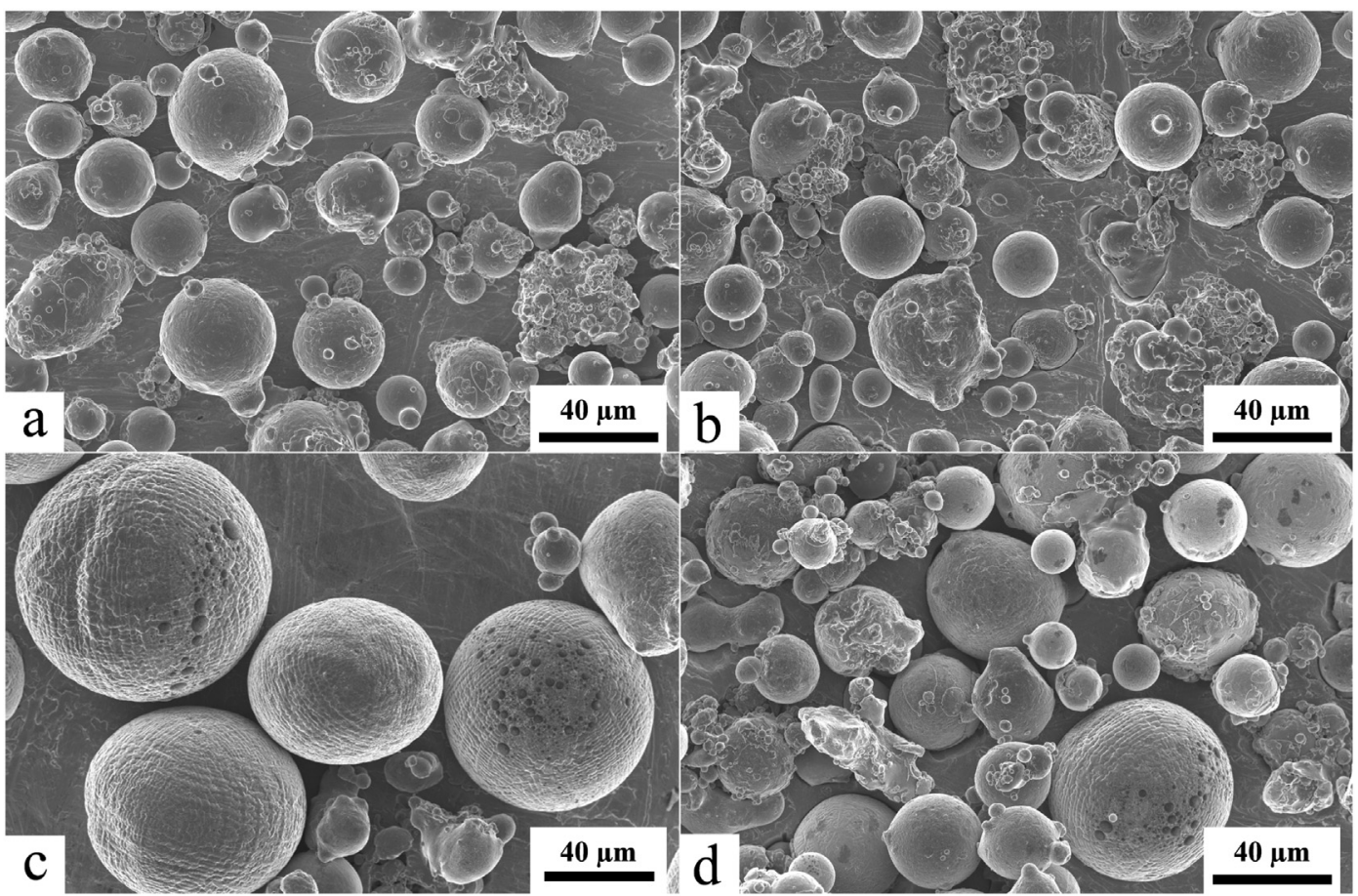

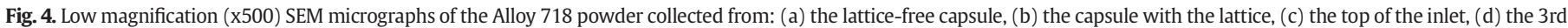
section of the outlet.

\section{Results and discussions}

Table 1 lists the amount and composition of all the powder samples collected after the print was completed. It can be noted that most of the spatter went into the 3rd section of the outlet (see Fig. 3 and Table 1). This is owing to the fact that the 3rd section has the most central position with respect to the build area, therefore a higher number of particles is collected at this spot. Some spatters originating closer to the outlet and/or having higher trajectories fell on top of the outlet. Some small amount of spatter travelled against the gas flow and fell on the gas inlet. This suggests that the kinetic energy of some particles at their emission is higher than the drag force of the opposing gas
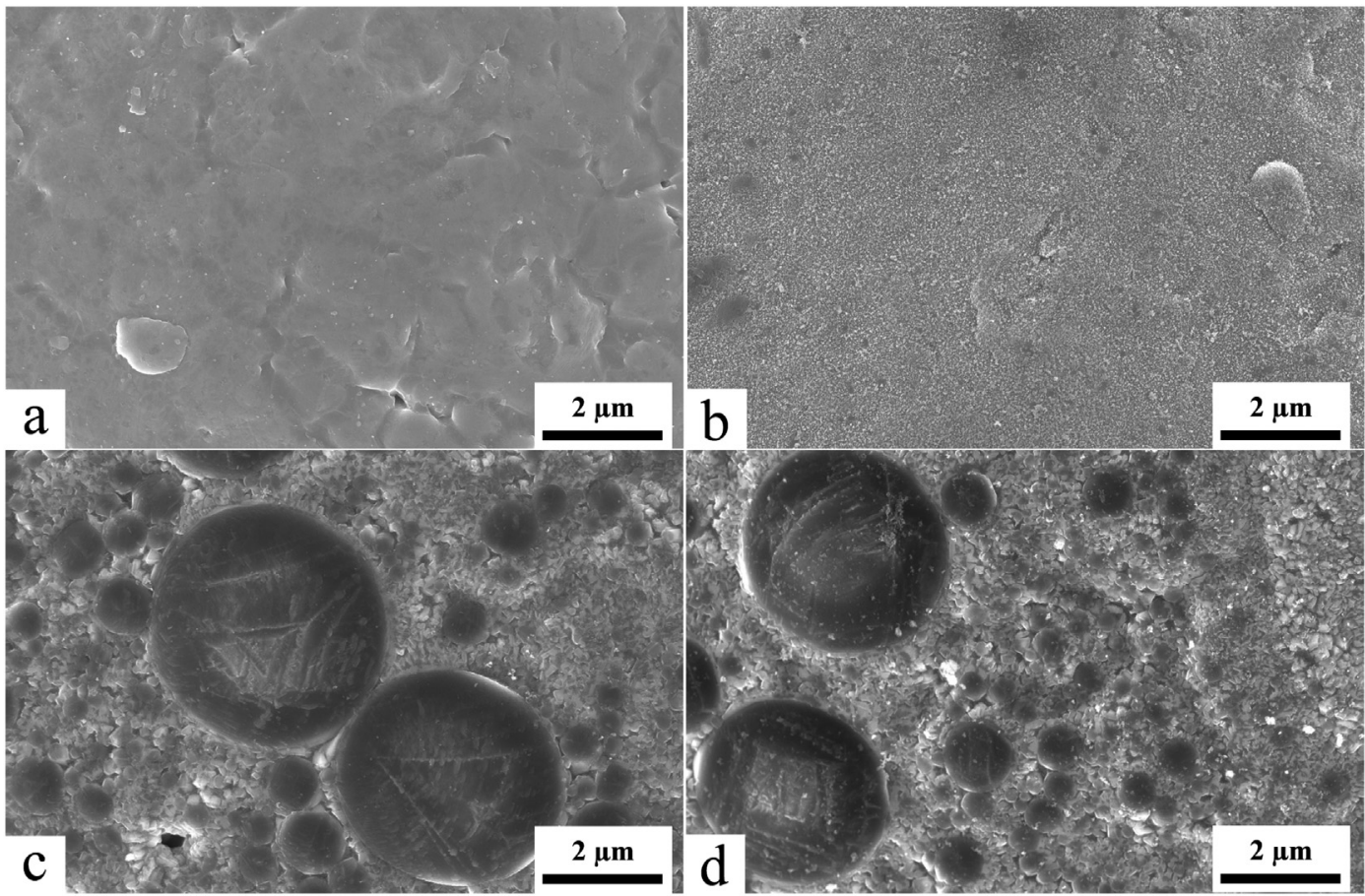

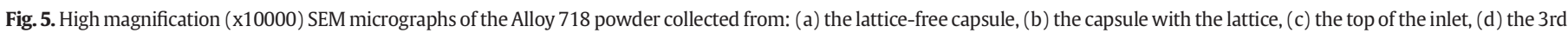
section of the outlet. 


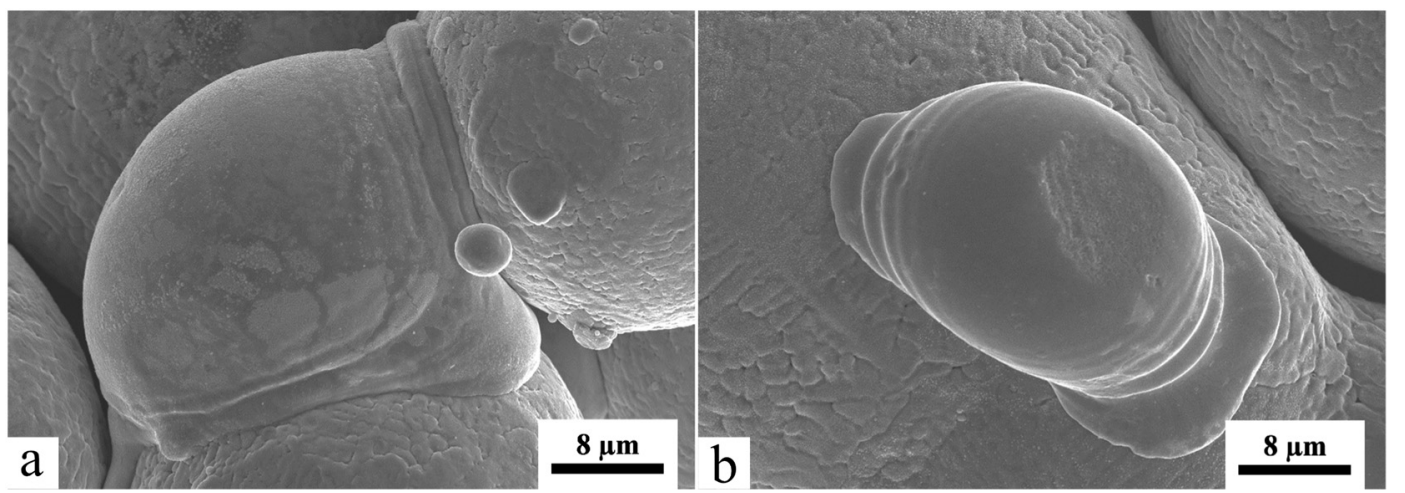

Fig. 6. SEM micrographs of Alloy 718 melt ejecta produced during L-PBF.

flow. In addition, it appears that the powder samples collected in the outlet are richer in oxygen towards the right sections. Since the build job was designed to be symmetrical, and the laser scanning is rotated between each layers, it may be connected to local variations in the gas flow over the baseplate, indicating needs for further studies of the gas flow properties on the spatter formation and removal during L-PBF processing.

In addition, it can be noted that the virgin powder and the powder from the capsules have relatively similar oxygen and nitrogen content. A slight oxygen increase (of the order of $10 \mathrm{ppm}$ ) for the powder surrounding the lattice structure is noted, that is believed to be connected to the higher fraction of spatter generated. It is evident that the particles collected outside the powder bed (consisting of both spatter and entrained particles) have a much higher oxygen content than the powder bed itself, about twice as high (about $600 \mathrm{ppm} \mathrm{O}_{2}$ ), while the nitrogen increase is of a few ppm only. This puts in evidence that spatters are also picking up a significant amount of oxygen from the L-PBF atmosphere. Therefore, reducing the residual oxygen available in the process chamber could be a solution to mitigate the spatter oxidation.

The as-built material appears to have the same nitrogen content as the virgin powder. And a slight oxygen decrease of about $30 \mathrm{ppm}$ (10\%) is noted from the powder to the cylinder, which is consistent with previously reported trend for 316L stainless steel [20,21]. This oxygen loss was attributed to the partial removal of surface bound oxygen during melting and oxygen removal by the process gas and spatter particles.

The spatter samples collected were too small to be able to run statistical PSD measurement by laser diffraction. Still, from low magnification SEM micrographs, the particle size appeared to remain rather unchanged among the virgin powder, the samples from the lattice-free and the capsule with lattice structures, and from the gas outlet (see Fig. 2a and Fig. 4a,b,d). However, the particles landing on the gas inlet appeared to belong to the high end of the PSD, with diameters typically larger than $\mathrm{D}_{90}$ (see Fig. 4c), which would not necessarily be sieved out before re-using powder for the next build when using sieve fabric mesh size of $63 \mu \mathrm{m}$, supplied with the EOS M290.

The powder within the lattice-free capsule is very similar to the virgin powder, with a clean surface, free of visible oxide features, see Fig. $5 \mathrm{a}$ and Fig. 2 b. The powder collected in the capsule with the lattice structure was relatively comparable. Still, at least $5 \%$ of the observed particles were characterized by very fine oxide particulates appearing with bright contrast in Fig. 5b. This oxidation initiation can be connected to the higher amount of melted surface and spatter generated, and the possible heat accumulation within the capsule which should be put in evidence in future work using monitoring tools. In addition, it should be stressed that the increased surface area of the lattice is accompanied by an increase of the contour to in-fill scanning ratio. Despite similar linear energy input of the contour and in-fill scanning parameter, it can't
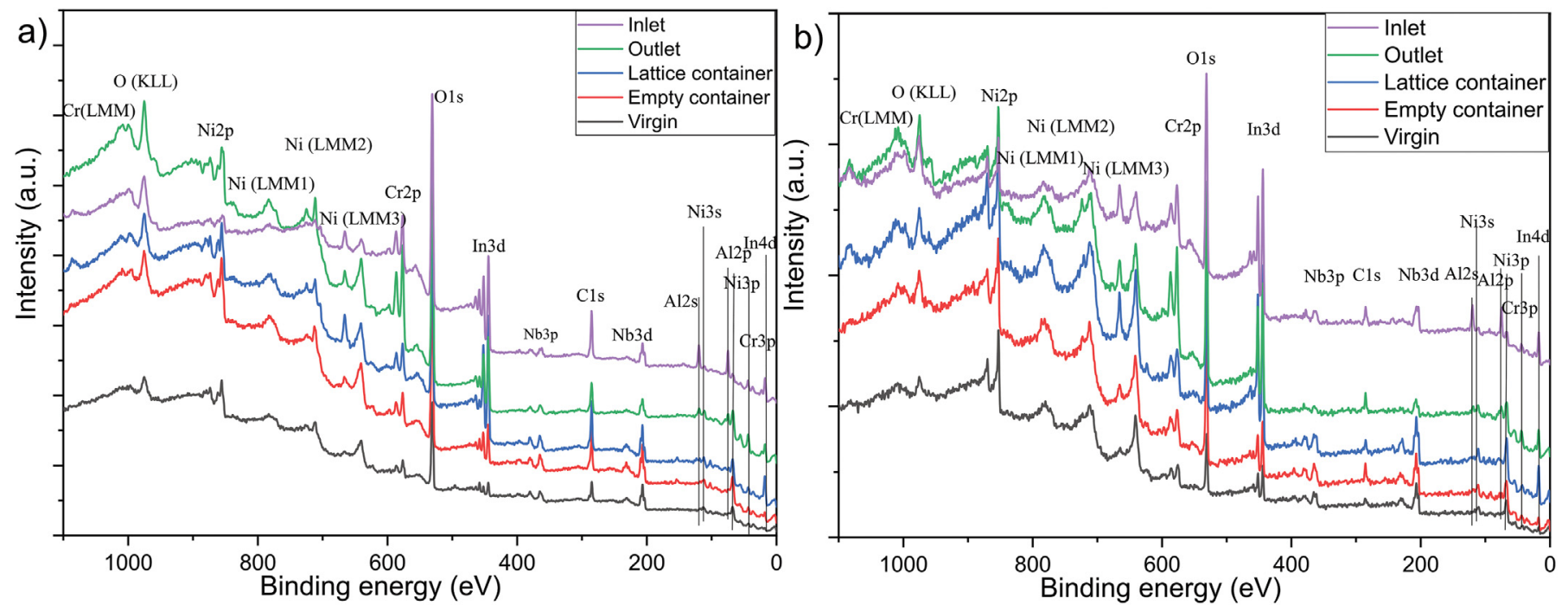

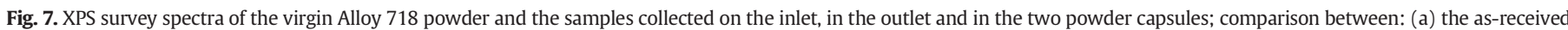
surfaces and (b) after $4 \mathrm{~nm} \mathrm{Ar}^{+}$etching. 

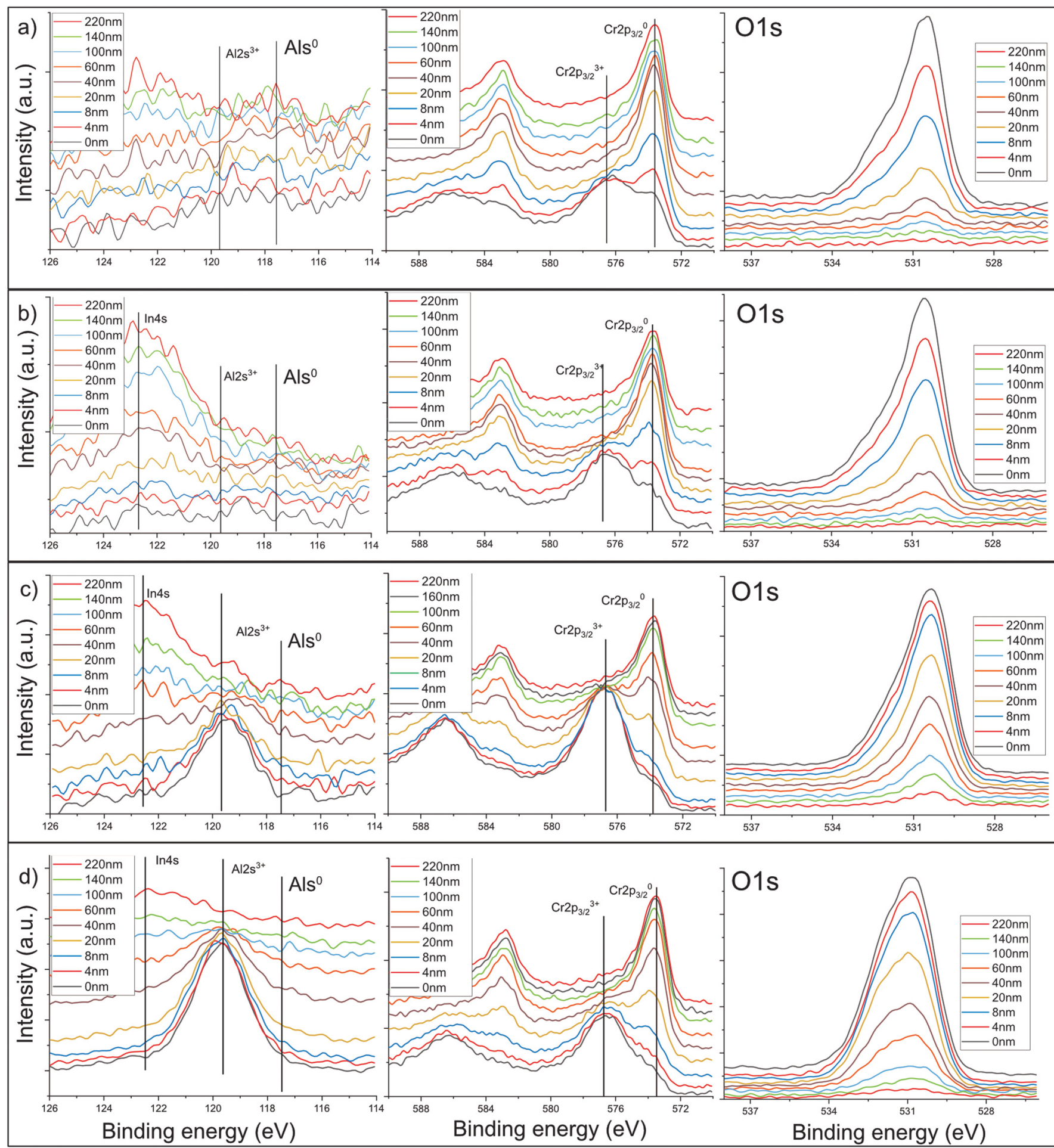

Fig. 8. Comparison of XPS depth profile of $\mathrm{Al}, \mathrm{Cr}$, and O spectra of a) empty capsule, b) lattice capsule, c) outlet spatters, and d) inlet spatters.

be dismissed that the contour scanning contributed to the overall spatter generation and increased oxidation.

The spatters from the top of the gas inlet and outlet are composed of particles with more pronounced oxidation as shown in Fig. 5 (c and d). These represent at least $60 \%$ of all particles for the inlet sample and $70 \%$ for the outlet. From EDS analysis, the oxidation features were identified as rich in $\mathrm{Al}$ and $\mathrm{Cr}$. The formation of Al-based oxides on Alloy 718 powders has already been reported after powder recycling in electron beampowder bed fusion (EB-PBF) [2].
In addition, as can be distinguished in the micrographs, some irregular particles are present both in the virgin powder and in the collected spatters. Their formation can have several origins occurring before or during the L-PBF process. During atomization, the collision of unsolidified droplets and solidified particles is common [22], and may result in the formation of fine satellites (a few can be distinguished on Fig. 2a) and agglomerations. In addition, particles which are satellitefree but have a more elongated shape because they are not completely spheroidized before solidification can be observed in the powder. 


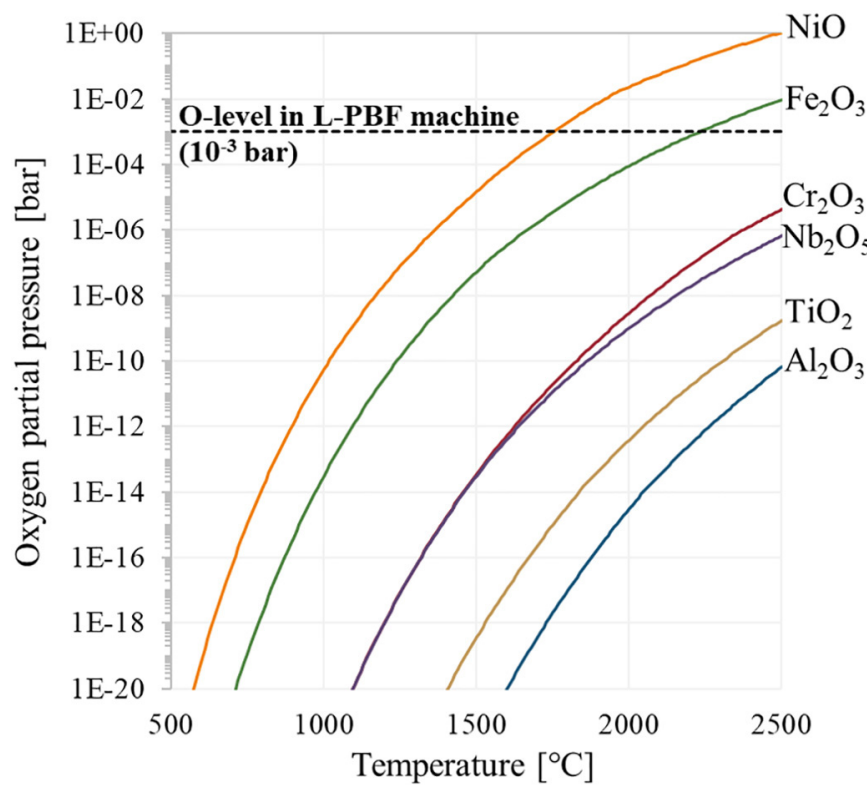

Fig. 9. Equilibrium partial pressure of oxygen for some metal/oxide systems of interest for Alloy 718 (calculated with HSC Chemistry version 10.0). The dotted line indicates the typical residual oxygen level during L-PBF.

These are seldom observed for the powder used in this work. Agglomeration in case of re-used powder can occur during the laser melting process as some melt is ejected from the laser-powder interaction zone. An example is presented in Fig. 6a which clearly shows the formation of the agglomerate by the spatter particle sintering together two virgin particles in the powder bed. This is confirmed by the absence of oxidation on the surfaces of virgin particles and a different microstructure (absence of dendrites on the surface) of the particle in between, indicating higher cooling rate of the spatter particle. Its surface is also partially oxidized, indicating once again its origin as a spatter. Fig. $6 \mathrm{~b}$ displays a second example of spatter feature which was produced from melt pool instability, also with a dendrite-free surface and bulges recalling liquid flow at the impact with the powder particle.

From Table 1, it is evident that the powder particles collected at the different positions outside of the powder bed are different in terms of extent of oxidation. This is owing to their different origin. From the chemistry analysis and the morphology analysis using SEM, it is clear that the particles which landed on the gas inlet are mostly large entrained particles which have experienced high temperatures leading to the formation of surface $\mathrm{Cr}$ - and Al-rich oxides. The particles which landed on the gas outlet are also mostly oxidized entrained particles. In addition, as the particles landing on the gas inlet travel against the gas flow, these are likely to have a higher initial kinetic energy than the ones landing on the outlet and thus to be larger. These typically have sizes similar to that of the particle observed in Fig. 2d, belonging to the high end of the PSD of the virgin powder. The particles inside the gas outlet are larger and richer in oxygen than the ones on top of it. The study of their morphology also highlights less entrained particles and more spatters than the particles deposited on the outlet. This suggests that more spatters travelled at lower height, following the protective gas stream.

The surfaces of the collected powder samples were further studied by means of XPS. The spectra of XPS analysis of the Alloy 718 powder samples (top of the inlet, in the outlet, in the capsules and virgin state) indicate the presence of the same elements on the surfaces: carbon (C1s), oxygen (01s), aluminum (Al2s), chromium ( $\mathrm{Cr} 2 \mathrm{p})$, nickel (Ni3p) and niobium (Nb3d). The indium peak (In3d) is coming from the substrate used for sample preparation, see Fig. 7. Fig. 7a shows a comparison of XPS spectra of the as-received surfaces. It can be observed that while the virgin powder and the empty capsule does not show presence of
$\mathrm{Al} 2 \mathrm{~s}$ and $\mathrm{Al} 2 \mathrm{p}$ peaks, the other samples containing process projections do. This Al2s peak appears with a relatively weak intensity for the sample in the capsule with lattice, which becomes more noticeable for the samples from the inlet and outlet. Likewise, the intensity of the Cr2p peak is relatively low for the virgin powder while it increases for the other samples and is the highest for the sample from the outlet. A similar trend in variation of relative intensities of various elements in powder samples can be observed at $4 \mathrm{~nm}$ etch depth as showed in Fig. $7 \mathrm{~b}$.

To further elucidate the amount and type of oxides on the surface of the samples, a depth profile analysis was performed by measuring narrow spectra of Al2s, Cr2p, and 01s at various etch depths, as given in Fig. 8. For peak shift adjustment, $\mathrm{Ni} 2 \mathrm{p}$ peak was used with the $\mathrm{Ni} 2 \mathrm{p}_{3 / 2}^{0}$ positioned at $852.5 \mathrm{eV}$.

The comparison of the Al2s spectra points out that the powders from the two capsules do not show noticeable intensity for this peak. This is attributed to the smaller fraction of spatters in the capsules, which from the Al2s spectra of the samples collected from the inlet and outlet are known to preferentially form Al-based surface oxides. Indeed, the spectra of the inlet and outlet samples exhibit a high intensity $\mathrm{Al} 2 \mathrm{~s}^{3+}$ peak which persists at higher etch depths. Given the small fraction of $\mathrm{Al}$ in Alloy 718, all the $\mathrm{Al}$ appearing on the surface exists in $\mathrm{Al}^{3+}$ form, and no metallic $\mathrm{Al}^{\circ}$ peak is identified.

Furthermore, a consistent increase in the intensity of the $\mathrm{Cr} 2 \mathrm{p}^{3+}$ peak positioned at $576.5 \mathrm{eV}$ can be observed close to the as-received surface for all samples. For the empty and lattice capsules, a strong metallic peak can be observed at $573.8 \mathrm{eV}$, even for an etch depth of $4 \mathrm{~nm}$ indicating a small thickness of the $\mathrm{Cr}$ oxide islands. Furthermore, a slight variation in the intensity of $\mathrm{Cr} 2 \mathrm{p}_{3 / 2}^{0}$ at $573.8 \mathrm{eV}$ can be observed for the lattice capsule compared to the empty capsule. Indeed, for the empty capsule the intensity of $\mathrm{Cr}_{2} \mathrm{p}_{3 / 2}^{0}$ is higher than that of $\mathrm{Cr} 2 \mathrm{p}_{3 / 2}^{3 / 2}$ $(576.5 \mathrm{eV}$ ) at $4 \mathrm{~nm}$ etch depth, which is not the case for the lattice capsule. This difference is primarily attributed to the presence of some fraction of spatter in the lattice capsule. For the inlet and outlet powder samples, the appearance of the $\mathrm{Cr} 2 \mathrm{p}_{3 / 2}^{3}+$ highlights the formation of thick $\mathrm{Cr}$-based oxide features.

The formation of thick oxide particulates and patches on the inlet and outlet samples comes from the origin of the spatter, which were ejected in either molten or partially molten state. Higher susceptibility of $\mathrm{Al}$ along with $\mathrm{Cr}$ drove their preferential oxidation at the surface. The intensity of the oxygen peak positioned at $531 \mathrm{eV}$ also remains higher at increasing etched depth for the inlet and outlet samples compared to the powder from

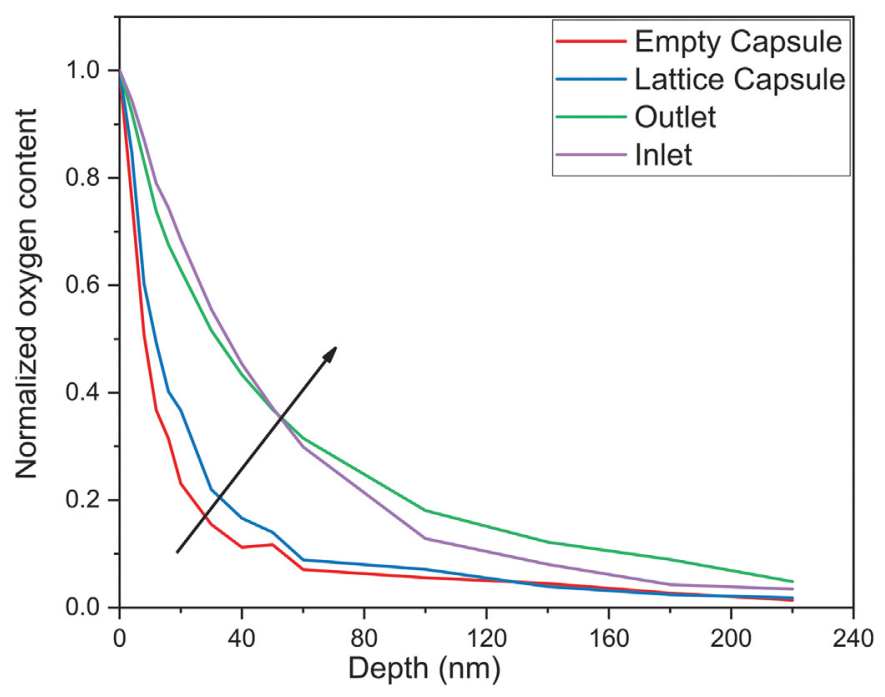

Fig. 10. A comparison of oxygen depth profile using normalized oxygen content for the Alloy 718 powder samples studied. 


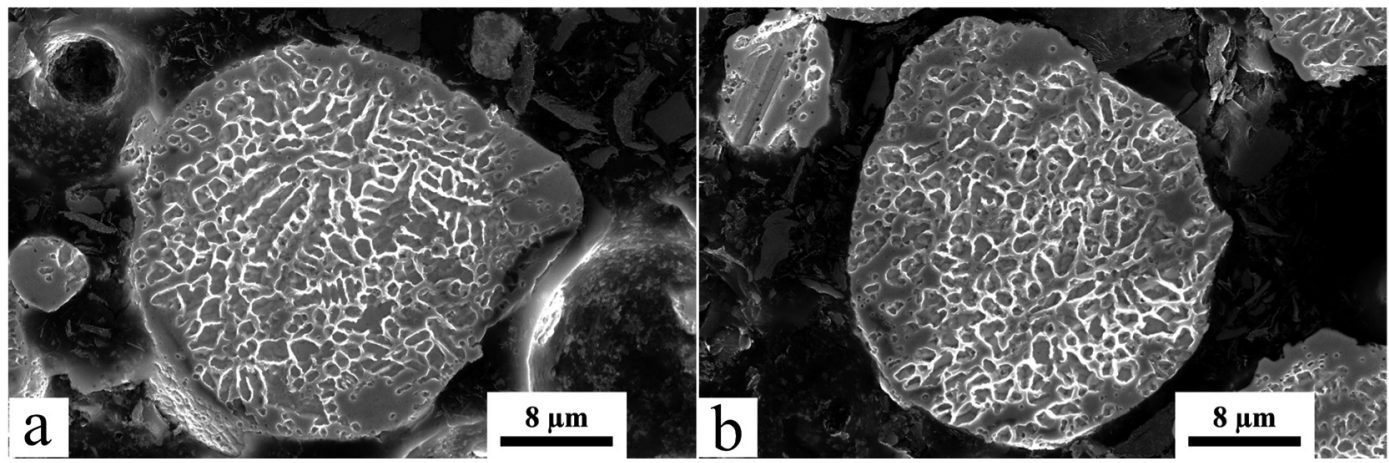

Fig. 11. SEM micrographs of etched cross-sections of virgin Alloy 718 powder particles.

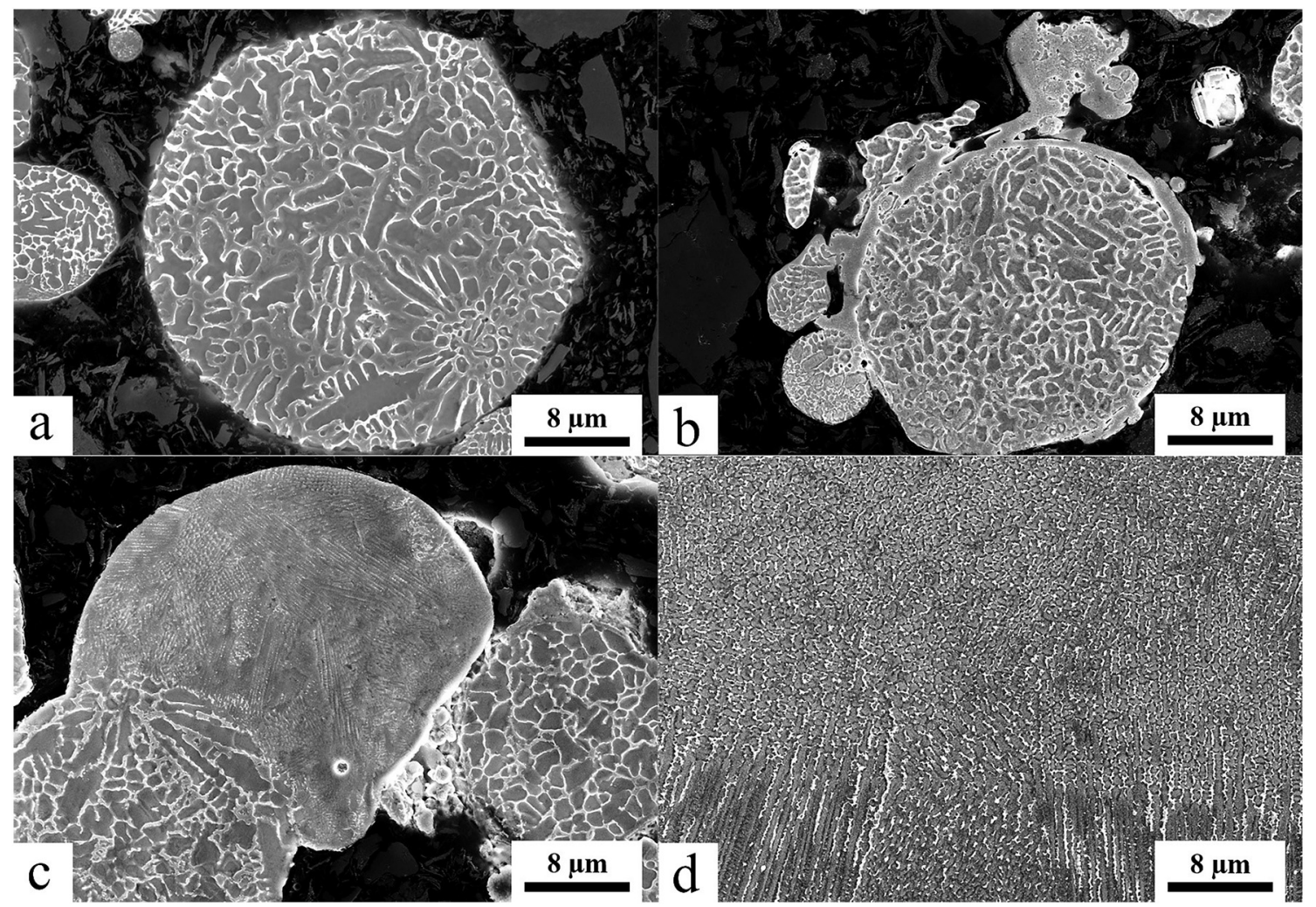

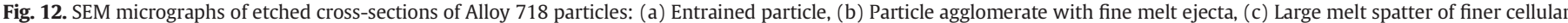
microstructure reminding that produced by the L-PBF process (d).

the capsules, indicating larger thickness of oxide particulate features. The larger thickness of oxide features is further confirmed by the analysis of the normalized oxygen intensity as a function of etched depth for the investigated samples [23], see Fig. 10.

The thermodynamic stability of oxides that may be formed in Alloy 718 is dependent on temperature and oxygen partial pressure, as presented in Fig. 9 for pure metal/oxide systems. Each plotted curve corresponds to a metal/oxide system (e.g., $\mathrm{Ni} / \mathrm{NiO}$ ), so that above the curve (for higher oxygen partial pressure) the element is stable in its oxide state, while below it tends to be reduced to its metal state. As can be seen, the residual oxygen level during L-PBF can be considered rather elevated as all listed elements are stable as oxides below approx. $1750{ }^{\circ} \mathrm{C}$. Despite this high oxygen level and the high cooling rates involved during L-PBF, the plot is a good indicator of which elements tend to preferentially oxidize during L-PBF of Alloy 718 ( $\mathrm{Al}$ and $\mathrm{Cr}$ ) and supports the interpretation of the spatter surface analysis.
It is evident that oxygen content increases from the empty capsule sample (which is very similar to the virgin powder) to the inlet and outlet samples. The increase of normalized oxygen content from the empty to the lattice capsule highlights the effect of the lattice geometry and increased scanned surface on the generation of spatters and the

Table 2

Primary and secondary dendrite arm spacing for the Alloy 718 powder particles, the melt ejecta (collected in the 3rd section of the outlet) and the bulk of the as-built material are displayed, as well as the standard deviation of the measurements. The estimated cooling rate calculated from Eq. (2) are also listed using $\left(C_{1}=105 \mathrm{~nm} ; \mathrm{n}_{1}=-0.31\right)$.

\begin{tabular}{llll}
\hline Sample & Average $\lambda_{1}[\mathrm{~nm}]$ & Average $\lambda_{2}[\mathrm{~nm}]$ & Estimated $\dot{T}[\mathrm{~K} / \mathrm{s}]$ \\
\hline Powder particles & $1107 \pm 268$ & $824 \pm 186$ & $2.4 \cdot 10^{6}$ \\
Melt ejecta & $254 \pm 32$ & N.A. & $2.9 \cdot 10^{8}$ \\
As-built Alloy 718 & $547 \pm 115$ & N.A. & $2.2 \cdot 10^{7}$ \\
\hline
\end{tabular}




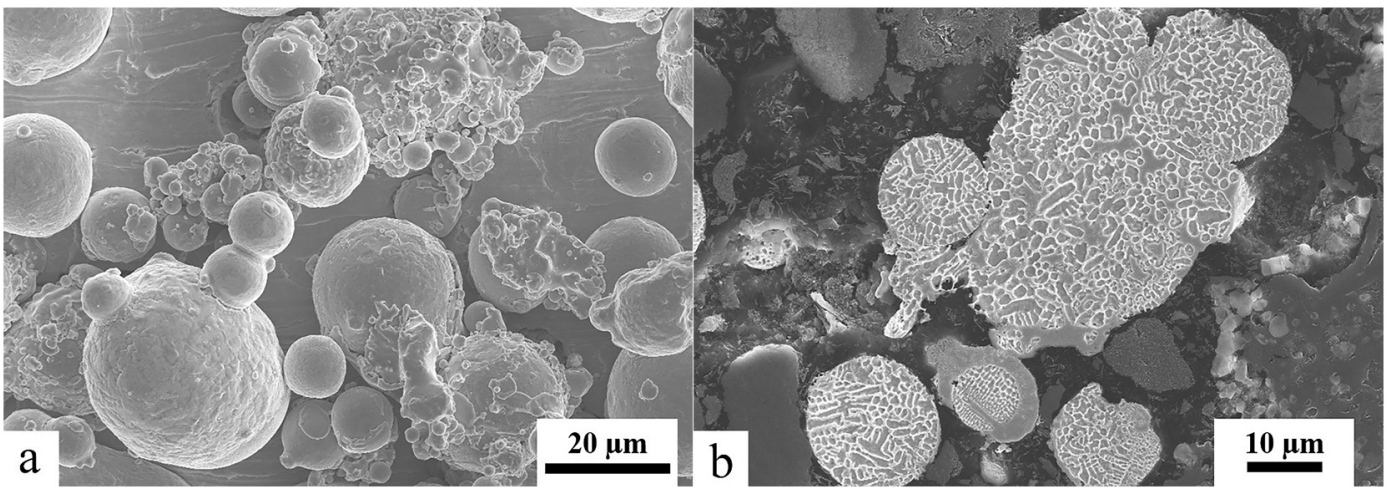

Fig. 13. (a) SEM micrograph of the morphology of the Alloy 718 powder particles remaining on the 63 um sieve, (b) and their etched cross-sections.

degradation of exposed powder particles. The inlet and outlet powders consist mostly of spatters which have a higher surface coverage by Aland $\mathrm{Cr}$-rich oxides as formerly discussed, and thus resulted in a higher oxygen content measured at larger etch depths. It appears therefore critical to discard these powders using a vacuum cleaner, to not conserve them through a re-use cycle, as they would potentially pass through a $63 \mu \mathrm{m}$ sieve.

The further in-depth analysis by HR SEM allowed to distinguish differences in thermal history between the powder particles collected. Fig. 11 and Fig. 12 display the cross-section of virgin powder particles and of the main types of particles in the collected powder in the outlet (3rd section), respectively. Among the particles presented in Fig. 12 are entrained powder particles which are slightly affected or not by the high temperature process, as displayed in Fig. 12a. The extent of oxidation of these particles was discussed previously based on the SEM and XPS analyses. Particles which were entrained and collided with fine spatter, that is still in a molten state, are also commonly observed, and are forming agglomerates with finer particles as seen in Fig. 12b. Finally, larger melt ejecta or spatters exhibiting a much finer microstructure than the virgin powder particles can easily be distinguished, see for example Fig. 12c, which can directly be connected to Fig. $6 a$. This fine microstructure obviously recalls the as-built microstructure of Alloy 718 obtained by the L-PBF process (see Fig. 12d). The microstructural variations are connected to significant differences in cooling rate during solidification between the powder during atomization, solidification of the spatter and deposited material. While both primary and secondary dendrites can be seen for the virgin powder and entrained particles, only primary dendrites are distinguished for the melt ejecta and the as-built material.

Kurz and Fisher [24] showed that for columnar growth solidification, the primary dendrite arm spacing (PDAS, $\lambda_{1}$ ) can be related to the temperature gradient $(G)$ and the growth rate $(R)$ by the relation:

$\lambda_{1}=4.3\left(\frac{\Delta T^{\prime} \cdot D_{L} \cdot \Gamma}{k}\right)^{0.25} \cdot R^{-0.25} \cdot G^{-0.5}$

where $\Delta T^{\prime}$ is the liquid-solidus interval, $D_{L}$ is the diffusion coefficient in the liquid, $\Gamma$ is the Gibbs-Thomson coefficient and $k$ is the partition ratio.

It has been shown that the following empirical relations connect $\lambda_{1}$ to the local cooling rate $(\dot{T}=G \cdot R)$ :

$\lambda_{1}=C_{1}(\dot{T})^{n_{1}}$

where the constants $C_{1}$ and $n_{1}$ are derived experimentally. Wang and Chou [25] have used $C_{1}$ and $n_{1}$ values derived for other conventional processes by Wang et al. [26], Bouse and Mihalisin [27] and Won et al. [28], and extensive dendrite size measurements to estimate the cooling rates of Alloy 718 built by L-PBF. Table 2 lists the measured primary and secondary dendrite arm spacing measured using Image for the particles which retained their virgin microstructure, the spatters and that of the as-built material (measured within the bulk). The cooling rates were estimated using a $C_{1}$ of $105 \mathrm{~nm}$ and $n_{1}$ of -0.31 [25,26], derived from rapid laser surface melting and re-solidification of a Ni-base superalloy. It is evident that the cooling rates during atomization are about one order of magnitude lower than that occurring during L-PBF of Alloy 718. The spatters appear to have experienced even higher cooling rate, which is connected to the as-built material being re-melted several layers and experiencing less steep cooling rates.

Fig. 13 displays micrographs of powder particles collected after the build job within the build volume, that did not pass through the $63 \mu \mathrm{m}$ sieve during powder sieving after L-PBF processing, and are therefore removed from the system. All the observed particles are characterized by critical agglomeration and some extent of oxidation. However, many non-agglomerated but significantly oxidized particles (as shown in Fig. 4(c and d)) are still within the tolerated particle's size distribution, and can pass through the sieve and remain in the process chain. Hence, it is misleading to assume that entrained powder particles and spatter are removed by powder sieving after L-PBF processing. Thus, it is important to follow powder degradation during L-PBF processing as there are evident changes in powder surface chemistry. This is in general related to the oxygen content of the powder after re-use but do not really represent the type and amount of spatter particles and melt ejecta in the powder after L-PBF processing. Further research is needed to find a connection between the surface chemistry of the powder and more general chemical and physical properties of powder ( $\mathrm{O}$ and/or $\mathrm{N}$ content, rheological properties, etc.), to be able to establish limits of powder re-use for specific materials and L-PBF hardware. This study also clearly shows that rough number of re-use cycles do not directly represent potential powder degradation during L-PBF processing, as it is also strongly determined by the component geometry and density of the components in the build volume.

\section{Conclusions}

The present work establishes the impurity balance, the nature of process projections including spatters and entrained particles, their surface oxidation states and the effect of design features on the degradation of the Alloy 718 powder during L-PBF processing. Taking into account high importance of process robustness during L-PBF processing of 718 components, typically aimed for high-end applications in aerospace and energy sectors, the following conclusions can be made based on the results of this work:

- Powder landing on the gas inlet consists mostly of large particles (above $\mathrm{D}_{90} \sim 50 \mu \mathrm{m}$ ) belonging to the high end of the virgin powder PSD, entrained during the process and travelling against the gas 
flow. These particles have experienced high temperatures as they were coming from close to the laser-metal interaction zone and are richer in oxygen (about double oxygen level), that is present as Aland $\mathrm{Cr}$-rich surface oxides.

- Powder landing on the gas outlet also consists of entrained particles but of smaller size, similar to the virgin powder, which travelled towards the gas flow but at a higher height. Like the spatters from the gas inlet, they are also rich in oxygen and mostly covered with Aland $\mathrm{Cr}$-rich oxide features.

- The important oxygen pick-up of spatters, well above the oxygen content in the feedstock powder, proves a significant pick-up of impurities from the L-PBF atmosphere by the particles exposed to the process conditions.

- Finally, it was shown that accelerated spatter generation is characteristic for L-PBF processing of components with designs characterized by high surface-to-volume ratio, such as lattice structures, which are of high interest for complex light-weight components. This results in increased pick-up of oxygen by the powder bed (on the order of tens of ppm) in proximity to such components, related to the higher fraction of generated spatter particles.

These conclusions will serve in the common effort to establish guidelines for powder recyclability and the study of the effect of the L$\mathrm{PBF}$ atmosphere impurities on the exposed material. The study also shows potential of utilization of set of empty and dense lattice containing containers for evaluation of the powder degradation for specific material, component design, hardware and L-PBF process.

\section{Credit author statement}

Camille Pauzon: Conceptualization; Methodology; Investigations; Formal analysis; Writing - original draft. Ahmad Raza: Conceptualization; Investigations; Formal analysis; Writing - original draft. Eduard Hryha: Conceptualization; Methodology; Funding acquisition; Project administration; Supervision; Writing - review \& editing. Pierre Forêt: Resources; Supervision; Writing - review \& editing.

\section{Declaration of Competing Interest}

The authors declare that they have no known competing financial interests or personal relationships that could have appeared to influence the work reported in this paper.

\section{Acknowledgments}

This work was conducted in the framework of the Centre for Additive Manufacturing - Metal $\left(\mathrm{CAM}^{2}\right)$, supported by the Swedish Governmental Agency of Innovation Systems (Vinnova).

\section{References}

[1] S. Ly, A.M. Rubenchik, S.A. Khairallah, G. Guss, J. Manyalibo, Metal Vapor Micro-jet Controls Material Redistribution in Laser Powder Bed Fusion Additive Manufacturing, 2017 1-12, https://doi.org/10.1038/s41598-017-04237-z.

[2] H. Gruber, M. Henriksson, E. Hryha, L. Nyborg, Effect of powder recycling in electron beam melting on the surface chemistry of alloy 718 powder, Metall. Mater. Trans. A 50 (n.d.) 4410-4422. doi:https://doi.org/10.1007/s11661-019-05333-7.

[3] E. Hryha, R. Shvab, H. Gruber, A. Leicht, L. Nyborg, Surface oxide state on metal powder and its changes during additive manufacturing : an overview, La Metall. Ital. (2018) 34-39http://www.aimnet.it/la_metallurgia_italiana/2018/marzo/hryha.pdf.
[4] P. Camille, H. Eduard, F. Pierre, N. Lars, Effect of the Residual Oxygen Content in the Processing Atmosphere on the Properties of Stainless Steel 316L Built by Laser Powder Bed Fusion, 2018, WorldPM, Beijing, 2018 1629-1632.

[5] M. Schniedenharn, J.H. Schleifenbaum, On the correlation of the shielding gas flow in L-PBF machines with part density, DDMC2018 Fraunhofer Direct Digit. Manuf. Conf 2018, pp. 1-7.

[6] M. Schniedenharn, F. Wiedemann, J.H. Schleifenbaum, Visualization of the shielding gas flow in SLM machines by space-resolved thermal anemometry, Rapid Prototyp. J. 24 (2018) 1296-1304, https://doi.org/10.1108/RPJ-07-2017-0149.

[7] X. Zhang, B. Cheng, C. Tuffile, Simulation study of the spatter removal process and optimization design of gas flow system in laser powder bed fusion, Addit. Manuf. 32 (2020)https://doi.org/10.1016/j.addma.2020.101049.

[8] J. Yin, D. Wang, L. Yang, H. Wei, P. Dong, L. Ke, G. Wang, H. Zhu, X. Zeng, Correlation between forming quality and spatter dynamics in laser powder bed fusion, Addit. Manuf. 31 (2019) 100958, https://doi.org/10.1016/J.ADDMA.2019.100958.

[9] P. Bidare, I. Bitharas, R.M. Ward, M.M. Attallah, A.J. Moore, Laser powder bed fusion in high-pressure atmospheres, Int. J. Adv. Manuf. Technol. (2018) 1-13, https://doi. org/10.1007/s00170-018-2495-7.

[10] A.N.D. Gasper, D. Hickman, I. Ashcroft, S. Sharma, X. Wang, B. Szost, D. Johns, A.T Clare, Oxide and spatter powder formation during laser powder bed fusion of Hastelloy X, Powder Technol. 354 (2019) 333-337, https://doi.org/10.1016/j. powtec.2019.06.004.

[11] A.N.D. Gasper, B. Szost, X. Wang, D. Johns, S. Sharma, A.T. Clare, I.A. Ashcroft, Spatter and oxide formation in laser powder bed fusion of Inconel 718, Addit. Manuf. 24 (2018) 446-456, https://doi.org/10.1016/j.addma.2018.09.032.

[12] K. Dietrich, J. Diller, S. Dubiez-le Goff, D. Bauer, P. Forêt, The Influence of Oxygen on the Chemical Composition and Mechanical Properties of Ti-6Al-4V during Laser Powder Bed Fusion ( L-PBF ), 32, 2020https://doi.org/10.1016/j.addma.2019. 100980.

[13] C. Pauzon, E. Hryha, P. Forêt, L. Nyborg, Effect of argon and nitrogen atmospheres on the properties of stainless steel 316L parts produced by laser-powder bed fusion, Mater. Des. 107873 (2019)https://doi.org/10.1016/j.matdes.2019.107873.

[14] C. Pauzon, P. Forêt, E. Hryha, T. Arunprasad, L. Nyborg, Argon-helium mixtures as laser-powder bed fusion atmospheres: towards increased build rate of Ti-6Al-4V, J. Mater. Process. Technol. 116555 (2019)https://doi.org/10.1016/J.JMATPROTEC. 2019.116555.

[15] M.P. Haines, N.J. Peter, S.S. Babu, E.A. Jägle, In-situ synthesis of oxides by reactive process atmospheres during L-PBF of stainless steel, Addit. Manuf. 101178 (2020) https://doi.org/10.1016/j.addma.2020.101178.

[16] M. Simonelli, C. Tuck, N.T. Aboulkhair, I. Maskery, I. Ashcroft, R.D. Wildman, R. Hague, A study on the laser spatter and the oxidation reactions during selective laser melting of 316L stainless steel, Al-Si10-Mg, and Ti-6Al-4V, Metall. Mater. Trans. A Phys. Metall. Mater. Sci. 46 (2015) 3842-3851, https://doi.org/10.1007/ s11661-015-2882-8.

[17] A. Raza, T. Fiegl, I. Hanif, A. Markström, M. Franke, C. Körner, E. Hryha, Degradation of AlSi10Mg powder during laser based powder bed fusion processing, Mater. Des. 198 (2021) 109358, https://doi.org/10.1016/j.matdes.2020.109358.

[18] A. Mitchell, A.J. Schmalz, C. Schvezov, S.L. Cockroft, The precipitation of primary carbides in Alloy 718, Superalloys 718, 625, 706 Var. Deriv, The Minerals, Metals \& Materials Society 1994, pp. 65-78, https://doi.org/10.7449/1994/superalloys_ 1994_65_78.

[19] Imagej: Image Processing and Analysis in Java, (n.d.). https://imagej.nih.gov/ij/ index.html (accessed March 2, 2020).

[20] C. Pauzon, E. Hryha, P. Forêt, L. Nyborg, Effect of argon and nitrogen atmospheres on the properties of stainless steel $316 \mathrm{~L}$ parts produced by laser-powder bed fusion, Mater. Des. 179 (2019) 107873, https://doi.org/10.1016/j.matdes.2019.107873.

[21] C. Pauzon, A. Leicht, U. Klement, P. Forêt, E. Hryha, Effect of the process gas and scan speed on the properties and productivity of thin 316L structures produced by laserpowder bed fusion, Metall. Mater. Trans. A (2020)https://doi.org/10.1007/s11661020-05923-w.

[22] U. Fritsching, V. Uhlenwinkel, Hybrid gas atomization for powder production, Powder Metall. (2012)https://doi.org/10.5772/35807.

[23] E. Hryha, C. Gierl, L. Nyborg, H. Danninger, E. Dudrova, Surface composition of the steel powders pre-alloyed with manganese, Appl. Surf. Sci. 256 (2010) 3946-3961, https://doi.org/10.1016/j.apsusc.2010.01.055.

[24] W. Kurz, D.J. Fisher, Fundamentals of Solidification, Fourth revised ed., 1998.

[25] X. Wang, K. Chou, Effects of thermal cycles on the microstructure evolution of Inconel 718 during selective laser melting process, Addit. Manuf. 18 (2017) 1-14 https://doi.org/10.1016/j.addma.2017.08.016.

[26] H.M. Wang, J.H. Zhang, Y.J. Tang, Z.Q. Hu, N. Yukawa, M. Morinaga, Y. Murata, Rapidly solidified MC carbide morphologies of a laser-glazed single-crystal nickel-base superalloy, Mater. Sci. Eng. A 156 (1992) 109-116, https://doi.org/10.1016/09215093(92)90421-V.

[27] G.K. Bouse, J.R. Mihalisin, Metallurgy of Investment Cast Superalloy Components, Academic Press, INC, 1989https://doi.org/10.1016/b978-0-12-690845-9.50010-5.

[28] Y.M. Won, K.H. Kim, T.J. Yeo, K.H. Oh, Effect of cooling rate on ZST, LIT and ZDT of carbon steels near melting point, ISIJ Int. 38 (1998) 1093-1099, https://doi.org/10. 2355/isijinternational.38.1093. 